\title{
Health Politicization and Misinformation on Twitter. A Study of the Italian Twittersphere from Before, During and After the Law on Mandatory Vaccinations
}

\author{
Nicola Righetti \\ University of Urbino Carlo Bo \\ nicola.righetti@uniurb.it \\ April, 2020 - Working Paper
}

\begin{abstract}
In July 2017, a law aimed at reversing the decline in vaccination coverage (Law 119/2017) made child vaccination mandatory in Italy. The law sparked a heated debate which was a breeding ground for disinformation and misinformation but also set the stage for some initiatives that have been trying to fight the problem. This paper analyzes the Twitter vaccine-related information environment by focusing on the information sources shared by about 500,000 tweets published from 18 months before to 18 months after the promulgation of the Law 119/2017 (three years), it highlights clusters of sources shared by the users and changes in problematic and quality information over time. Results show that the politicization of the topic was associated with a growing spread of misinformation, and that the vaccine-related information environment is characterized by an homophilic and polarized structure grouping together and opposing, on the one side, anti-vaccinations, blacklisted sources, alternative therapy and conspiracy websites, and on the other side, scientific and health sources. Moreover, despite the new initiatives aimed at increasing the quality of online information and fighting misinformation and "fake news", there was a relative lack of scientific information both during and after the debate on the vaccinations law, while problematic information seems to have grown over the three years taken into consideration.

Keywords: Disinformation, Social Media, Vaccine, Twitter, Health Disinformation, Anti-Vaccine Movement
\end{abstract}

\section{Introduction}

Concern over the spread of problematic information on social media has increased in the last few years. Misinformation and disinformation ${ }^{1}$ erode trust in public institutions, undermine political processes (Lazer et al., 2018; Tucker et al., 2018) and pose a danger for public health. Vaccine misinformation is a case in point: viral misinformation eroding trust in vaccines (Kata, 2010, 2012) can impact on vaccine hesitancy (Dube, Vivion, \& MacDonald, 2015; European

\footnotetext{
${ }^{1}$ Terms such "misinformation" and "disinformation" have different meanings (e.g. Wardle, Derakhshan, 2017). However, for the sake of simplicity, the term "misinformation" or "problematic information" will be used in this paper to refer to intentionally or unintentionally false or misleading information.
}

Commission, 2018, 2019; WHO, 2019a; WHO, 2019b) and even represent a pandemic risk (Larson, 2018).

Italy has been facing several problems with both political and scientific misinformation. The Italian authority for communications highlighted that the market share of misinformation strongly increased since the end of 2017, and science and technology topics account for about $19 \%$ of the overall market, second only to politics (57\%) (AGCOM, 2018). In Italy, political and health misinformation became crucial issues especially in 2017, when measles outbreak sickened thousands of people ${ }^{2}$ (Filia et al., 2017; ISS, 2019; WHO, 2019a), and political misinformation threatened the imminent general election of March 4, 2018 (Fletcher et al. 2018; Giglietto et al., 2018, 2019a, 2020). The so-called "Lorenzin decree" (named after the Italian Minister of Health in charge at that time, Beatrice Lorenzin), aimed at addressing declining vaccination uptake by introducing mandatory child vaccinations (Chirico, 2018; Signorelli, Odone, Cella, \& Iannazzo, 2018). The decree became law on July 31, 2017 (Law 119/2017), sparking a heated debate which provided fodder for political and health misinformation on social media and mainstream media (Casula \& Toth, 2018; Lovari et al., 2020). At the same time, many initiatives were born for trying to fight health misinformation and promote scientific, quality information on social media, as "Dottore, ma è vero che... ?" ("Doctor is it true that...?") (FNOMCeO, 2018), "ISS Salute" ("ISS Health") (ISS, 2018a), and "Medical Facts" (Burioni, 2018).

For all these reasons, Italy represents a privileged point of view on political and health misinformation processes. Using Twitter, a relevant social media with about 2.35 millions of Italian monthly active users (We Are Social, 2019), this paper leverages this national peculiarity in order to shed light on some questions relative to the spread of health misinformation, its relation with health politicization, the volume of scientific information, and the homophilic and polarized structure of the vaccine-related informative ecosystem.

\footnotetext{
${ }^{2}$ Since the beginning of 2013, 13,001 measles cases have been reported in Italy, of which 2,270 in 2013, 1,695 in 2014, 256 in 2015, 861 in 2016, 5,393 in 2017 and 2,526 in 2018 (ISS, 2019).
} 


\section{Research questions}

Many studies have been devoted to vaccine-related information and misinformation on mass media, the Internet and social media ${ }^{3}$. However, not much research has analyzed the vaccine-related debate on social media at the crossroads of a relevant policy change such as the Italian law on mandatory vaccinations. Recently, it has been observed that the conversations on Twitter increased before the approval of the law, and anti-vaccination tweets outweighed the pro-vaccination ones (Tavoschi et al., 2020), but there is a lack of studies focusing on what happened after the promulgation of the Law $119 / 2017$. This research started, therefore, by conducting an exploratory analysis aimed at discovering the trend of online conversations on the topic and the events that triggered them before, during and after the approval of the Lorenzin's law:

RQ1) Which was the volume of vaccine-related conversations on Twitter and which were the main events that triggered them before, during and after the discussion on the law on mandatory vaccinations?

Studying health and political information on social media can not disregard the fact that social media users tend to gather around like-minded communities driven by the homophily principle - the tendency of people to interact with similar others (Lazarsfeld \& Merton, 1954; McPherson, Smith-Lovin, \& Cook 2001) - and are considered at risk of ideological segregation and polarization (Dandekar, Goel, \& Lee, 2013; Pariser, 2011; Samantray \& Pin, 2019; Stroud, 2010; Sunstein, 2001b, 2001a). Although the impact of these communication phenomena should not be exaggerated (Bruns, 2019; Dubois \& Blank, 2018), homophily shapes, at least in part, the online environment (Bakshy, Messing, \& Adamic, 2015; Barberá, Jost, Nagler, Tucker, \& Bonneau, 2015; Colleoni, Rozza, \& Arvidsson, 2014; Conover et al., 2011), also with reference to vaccine-related communication (Schmidt et al., 2018). Since people also tend to gather around information sources consistent with their own viewpoint, and social media provide them the opportunity to share links, users' information sources preferences can emerge online (Bakshy et al., 2015; Faris et al.,

\footnotetext{
${ }^{3}$ A sample of the studies in the field can include, for instance: Ache \& Wallace, 2008; Bean, 2011; Betsch, Renkewitz, Betsch, \& Ulshöfer, 2010; Blankenship et al., 2018; Bodemer, Müller, Okan, Garcia-Retamero, \& Neumeyer-Gromen, 2012; Clarke, Dixon, Holton, \& McKeever, 2015; Briones, Nan, Madden, \& Waks, 2012; Broniatowski et al., 2018; Comunello, Mulargia, \& Parisi, 2017; Covolo, Ceretti, Passeri, Boletti, \& Gelatti, 2017; DanovaroHolliday, Wood, \& LeBaron, 2002; Dixon \& Clarke, 2013; Dunn et al., 2017; Donzelli et al., 2018; Ekram, Debiec, Pumper, \& Moreno, 2019; Fadda, Allam, \& Schulz, 2015; Ghanbari, Yousefi Nejad, Jafari Navimipour, \& Hosseinzadeh, 2019; Gollust, Attanasio, Dempsey, Benson, \& Fowler, 2013; Gollust, LoRusso, Nagler, \& Fowler, 2016; Habel, Liddon, \& Stryker, 2009; Hilton, Hunt, Langan, Bedford, \& Petticrew, 2010; Himelboim, Xiao, Lee, Wang, \& Borah, 2019; Grant et al., 2015; Kata, 2010, 2012; Lin \& Lagoe, 2013; Moran, Lucas, Everhart, Morgan, \& Prickett, 2016; Skea, Entwistle, Watt, \& Russell, 2008; Schmidt, Zollo, Scala, Betsch, \& Quattrociocchi, 2018; Smith, Ellenberg, Bell, \& Rubin, 2008; Speers \& Lewis, 2004; Tafuri et al., 2014; Ward, Peretti-Watel, Larson, Raude, \& Verger, 2015; Witteman \& Zikmund-Fisher, 2012.
}

2017; Giglietto et al., 2019b; Schmidt et al., 2017). The second research questions therefore asked:

RQ2) Did homophily determine the structure of the Twitter vaccine-related information environment? And if so, which were the main clusters of vaccine-related information sources?

Health and political misinformation can not be easily disentangled. As recently observed by Lovari, Martino and Righetti (2020), politicization can increase the spread of misinformation on vaccines "both directly and by opening the door to pseudoscientific and conspiratorial content (...) published by problematic news sources". As a consequence, the strong politicization of vaccines during the debate on the law on mandatory vaccinations could have increased the volume of problematic information already spread on the Internet by anti-vaccine activists questioning official medicine (Kata, 2010, 2012), sowing doubts on vaccines safety, and spreading conspiracy theories (Blaskiewicz, 2013; Douglas et al.; Mancosu, Vassallo, \& Vezzoni, 2017). In order to deepen our understanding of online misinformation, the link between political and health misinformation should be further explored. It was thus asked:

RQ3) Was the volume of problematic information sources shared on Twitter related to the politicization of the topic?

Social media can be means for misinformation but also tools for correcting "fake news" and disseminating high-quality health information (Bode \& Vraga, 2018; Gesser-Edelsburg, Diamant, Hijazi, \& Mesch, 2018.; Guidry et al., 2019; Harrison et al., 2016; Larson, 2018; Sastry \& Lovari, 2017; Vraga \& Bode, 2017; Zhang, Gotsis, \& Jordan-Marsh, 2013). Recently, social media and websites have started to be used to support vaccine uptake, fight health misinformation, and spread scientific information. Social media platforms such as Facebook, Pinterest and Twitter, have taken initiatives to limit misinformation around vaccines (Facebook, 2019; Pinterest, 2019; Twitter, 2019), and online communication campaigns and websites were launched in Italy to promote vaccine uptake and scientific information (Lovari et al., 2020). Examples of these initiatives are "Dottore, ma è vero che... ?" ("Doctor is it true that...?") (FNOMCeO, 2018), "ISS Salute" ("ISS Health") (ISS, 2018a), and "Medical Facts" (Burioni, 2018). Initiatives like these are important, but there is a lack of research trying to assess their impact, so it was asked:

RQ4) Were there changes over time in the type and quality of information sources shared on Twitter by the users that participated in the debate on vaccines?

\section{Data and Methods}

All the tweets containing any of the words "vaccino", "vaccini", "vaccinazione", "vaccinazioni", "vaccinare" published between 2016-02-01 and 2019-01-31 (three years) were gathered ${ }^{4}$. The three years time span includes 18 months before and after July 31, 2017, when the Italian law on mandatory vaccinations came into force. Around

\footnotetext{
${ }^{4}$ A Python script was used. Only public tweets were gathered, in accordance with all ethical standards.
} 


\begin{tabular}{llllllll}
\hline Period of Time & Tweets & Retweets & Likes & Replies & $\begin{array}{l}\text { Unique } \\
\text { Users }\end{array}$ & $\begin{array}{l}\text { Unique } \\
\text { URLs }\end{array}$ & $\begin{array}{l}\text { Unique } \\
\text { Domains }\end{array}$ \\
\hline $\begin{array}{l}\text { From 2016-02-01 } \\
\text { to 2019-01-31 }\end{array}$ & 484,618 & 948,329 & $1,930,590$ & 295,468 & 89,656 & 190,589 & 9,658 \\
\hline
\end{tabular}

Table 1: Descriptive statistics of the Italian dataset of tweets on vaccines.

\begin{tabular}{ccc}
\hline Metric & Categorized & Uncategorized \\
\hline Tweets & $152,224(82.14 \%)$ & $33,103(17.86 \%)$ \\
Likes & $274,134(86.28 \%)$ & $43,593(13.72 \%)$ \\
Retweets & $211,648(86.68 \%)$ & $32,522(13.32 \%)$ \\
Replies & $48,102(91.13 \%)$ & $4,683(8.87 \%)$ \\
\hline
\end{tabular}

Table 2: Tweets taken into consideration in the analysis (categorized) and excluded (uncategorized)

this date, the Twitter conversations on vaccines skyrocketed (Figure 1), and many initiatives were launched to counter related disinformation (Lovari et al., 2020).

The tweets unrelated to the topic (for instance those on animal vaccines or the band "The Vaccines") were removed. The dataset used for the analysis comprised 484,618 original tweets. All the links (URLs) posted in the tweets were extracted. Since Twitter shortens the links, they were converted back to their original form (Rudis, 2016). It was possible to identify 190,589 unique URLs (Table 1).

To focus on the most relevant information sources, all the subsequent analyses were conducted on the web domains shared at an above average rate ( $M=19, n=1022$ domains), corresponding to $82.14 \%$ of all the tweets that shared an URL (Table 2).

To answer the first question (RQ1: "Which was the volume of vaccine-related conversations on Twitter and which were the main events that triggered them before, during and after the discussion on the law on mandatory vaccinations?"), the daily time series of tweets was analyzed to identify the events that might have determined the observed peaks of attention to the topic. A structural break statistical analysis (Box-Steffensmeier et al., 2014; Zeileis et al., 2001) was run to identify possible periods marked by a statistically significant different number of tweets. Kruskal-Wallis test followed by Dunn's post-hoc test was used to assess statistically significant differences in the number of tweets and their engagement before, during and after the discussion on the Lorenzin decree.

To answer the second research question (RQ2: "Did homophily determine the structure of the Twitter vaccinerelated information environment? And if so, which were the main clusters of vaccine-related information sources?") a network was created, whose nodes were web domains (n $=1,022$ shared in $n=152,224$ tweets, which were all the domains shared an above average number of times, see Table 2), and whose edges were relations between domains. The author analyzed all the web domains included in the analysis and classified them into a taxonomy of information sources based on that of Love and colleagues (Love et al., 2013). The taxonomy included, for instance, the following categories: news media, conspiracy theory websites, alternative therapy websites, health specific sources, anti-vaccines and pro-vaccines sources, health organizations and scientific communication information sources. Moreover, the categories were supplemented by a list of 376 blacklisted web domains compiled by aggregating blacklists retrieved from established Italian debunking organizations (e.g. Fletcher et al., 2018; Giglietto et al., 2020; Lovari et al., 2020). Since every clustering method has its own limitations, six different clustering algorithms ${ }^{5}$ were used to identify the clusters of information sources. Using the results of the remaining four clustering methods (namely Louvain, Fast Greedy, Leading Eigenvector and Walktrap) it was run a correspondence analysis on the matrix $\mathrm{N}$ (clusters) x M (information source categories), eventually aggregating the group of categories distributed on the cartesian plane in the final clusters of information sources.

The third research question (RQ3: "Was the volume of problematic information sources shared on Twitter related to the politicization of the topic?"), was answered by using a breakpoints statistical analysis (Zeileis et al., 2001) to identify possible structural breaks in the time series of tweets sharing problematic information sources, and by comparing them with the events that led the conversation in that time. The rationale was that an association with politicization could result in a structural break in correspondence with the political debate on the mandatory vaccination law. Then, a time series regression model was fitted by using the following variables: a) the daily time series of the problematic information source cluster emerged from the previous step; b) the daily time series of Italian news stories on vaccines retrieved from MediaCloud ${ }^{6}$ using the same keywords used for gathering the tweets. This variable was used as a proxy for the media attention to the topic ${ }^{7}$ and as a control variable, since its possible relation with the volume of disinformation could confound the relation between politicization and misinformation; c) a dummy variable representing the structural break identified in the whole series of tweets. As it will be detailed in the next section, this structural break was clearly associated with the political debate on the mandatory vaccinations law and was thus used as a proxy for the politicization of the topic. A Vector Auto-Regressive model (VAR) was fitted to find possible statistically significant relations between the variables and, more specifically, between the spread of misinformation and the politicization of the topic.

The fourth and last research question (RQ4: "Were there changes over time in the type and quality of information

\footnotetext{
${ }^{5}$ The algorithms are included in the R package "igraph" (Csardi, Nepusz, 2006).

${ }^{6}$ MediaCloud (https://mediacloud.org) is an open-source platform for media analysis developed and maintained by the MIT Center for Civic Media and the Berkman Klein Center for Internet \& Society at Harvard University.

${ }^{7}$ Roughly the same results were found also by using, instead of the MediaCloud data, the series of tweets sharing domains categorized as news media.
} 


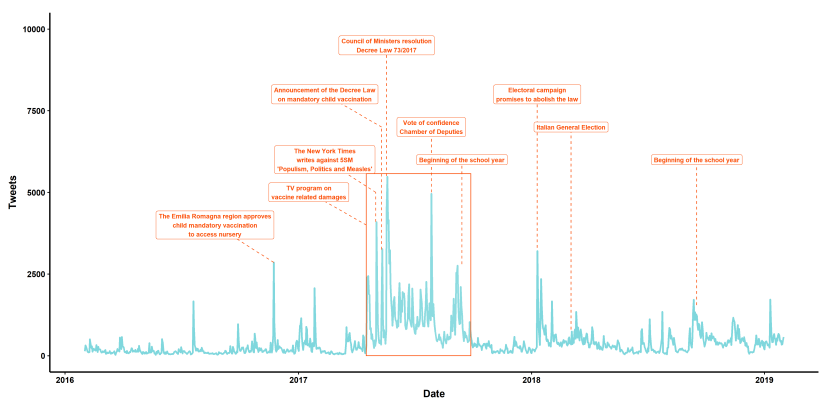

Figure 1: Annotated time series of the Italian tweets on vaccines. The red box indicates the boundaries of the structural break.

\begin{tabular}{|c|c|c|c|c|}
\hline Coefficients & Estimate & Std. Error & $t$ value & $\operatorname{Pr}(>|t|)$ \\
\hline $\begin{array}{l}\text { Segment } 1 \\
(2016-02-01 / 2017-04-17)\end{array}$ & 86.624 & 6.796 & 12.75 & $<0.001 * * *$ \\
\hline $\begin{array}{l}\text { Segment } 2 \\
(2017-04-18 / 2017-09-28)\end{array}$ & 420.555 & 11.156 & 37.70 & $<0.001 * * *$ \\
\hline $\begin{array}{l}\text { Segment } 3 \\
(2017-09-29 / 2019-01-31)\end{array}$ & 91.765 & 6.454 & 14.42 & $<0.001 * * *$ \\
\hline
\end{tabular}

Residual standard error: 142.9 on 1093 degrees of freedom

Multiple R-squared: 0.6203, Adjusted R-squared: 0.6193

F-statistic: 595.2 on 3 and 1093 DF, p-value: $<2.2 \mathrm{e}-16$

Table 3: Structural break analysis. A structural break emerged in the period of discussion and approval of the law on mandatory vaccination.

sources shared on Twitter by the users that participated in the debate on vaccines?") was answered by calculating the average number of tweets sharing information sources included in the identified clusters and comparing their change over time through "index numbers", a standard method to measure the change in a variable or group of variables over time. The R statistical software was used for all the analysis (R Core Team, 2019).

\section{Results}

Twitter conversations on vaccines reached the peak in the middle of 2017 (Figure 1), when the "Lorenzin's decree" on mandatory vaccines started to be debated and eventually became a law (Casula \& Toth, 2018; Tavoschi et al., 2020). The breakpoints statistical analysis (Zeileis et al., 2001) showed that this political event caused a significant shock on the usual flow of vaccine-related conversations on Twitter (Figure 1 and Table 3 ).

Another spike, while much less pronounced than the previous one, was associated with the 2018 electoral campaign, when the main political parties running for the 2018 Italian General Election made reference to the law on child vaccinations, either defending it or promising its abrogation $(\mathrm{Ca}-$ sula \& Toth, 2018; Lovari et al., 2020). Since the new law imposed vaccinations as a prerequisite to school admission, it is also not surprising to find peaks of conversations near

\begin{tabular}{ccc}
\hline & Segment 1 & Segment 2 \\
& $(2016-02-01 / 2017-04-17)$ & $(2017-04-18 / 2017-09-28)$ \\
\hline Segment 2 & -17.66337 & \\
$(2017-04-18 / 2017-09-28)$ & $0.0000^{*}$ & \\
Segment 3 & -2.943320 & 15.76200 \\
$(2017-09-29 / 2019-01-31)$ & $0.0049^{*}$ & $0.0000^{*}$ \\
\hline
\end{tabular}

Table 4: Volume of tweets before, during and after the discussion on the Lorenzin decree. Dunn's post-hoc test with Bonferroni correction.

\begin{tabular}{ccc}
\hline & Segment 1 & Segment 2 \\
& $(2016-02-01 / 2017-04-17)$ & $(2017-04-18 / 2017-09-28)$ \\
\hline Segment 2 & -18.31781 & \\
$(2017-04-18 / 2017-09-28)$ & $0.0000^{*}$ & 8.220182 \\
Skgment 3 & -14.22709 & $0.0000^{*}$ \\
\hline
\end{tabular}

Table 5: Tweets engagement before, during and after the discussion on the Lorenzin decree. Dunn's post-hoc test with Bonferroni correction.

the beginning of the school years.

Although the debate on mandatory vaccination fostered conversations on vaccine-related topics on Twitter in an unusual way, the discussions on the matter did not stop at all after that period. On the contrary, the daily volume of tweets (Kruskal-Wallis chi-squared $=328.1232, \mathrm{df}=2, \mathrm{p}$-value $=$ 0 , Table 4) as well as the engagement (Kruskal-Wallis chisquared $=397.9715, \mathrm{df}=2, \mathrm{p}$-value $=0$, Table 5 ) continued to be high, and even statistically significantly higher ( $\mathrm{p}<$ 0.001) than those of the first period.

With regard to the second research question (RQ2), the clustering analysis followed by correspondence analysis found four main clusters of information sources (Figure 2).

Unsurprisingly, and coherently with the homophily principle, anti-vaccine information sources were clustered together with conspiracy, alternative therapies, news blogs which are websites that publish articles for profit, to put forward a political agenda or as a hobby without being professional journalistic sources - and blacklisted websites,

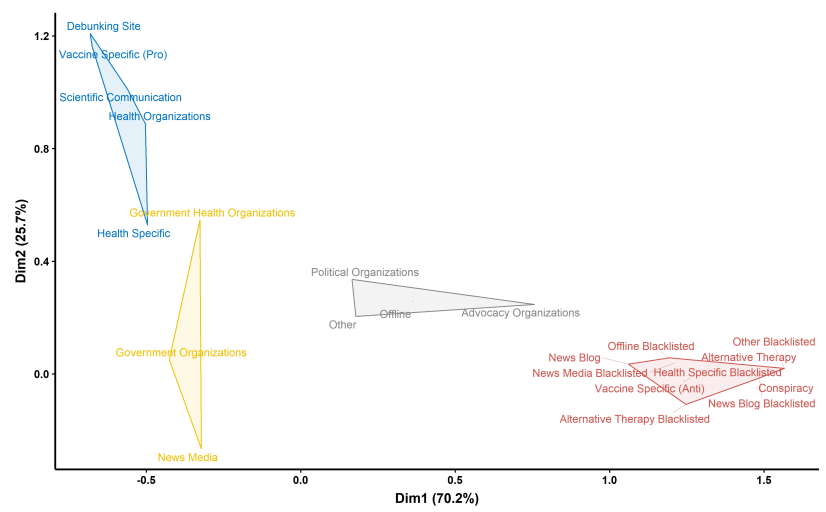

Figure 2: Clusters of information sources shared on Twitter 


\begin{tabular}{|c|c|c|c|c|}
\hline Coefficients & Estimate & Std. Error & t value & $\operatorname{Pr}(>|t|)$ \\
\hline Problematic Lag 1 & 0.53139 & 0.03005 & 17.685 & $<0.001 * * *$ \\
\hline News Lag 1 & 0.44717 & 0.10094 & 4.430 & $<0.001 * * *$ \\
\hline Problematic Lag 2 & 0.22529 & 0.02980 & 7.561 & $<0.001 * * *$ \\
\hline News Lag 2 & -0.17233 & 0.10107 & -1.705 & 0.0885 \\
\hline Const & 0.47187 & 0.05727 & 8.240 & $<0.001 * * *$ \\
\hline $\begin{array}{l}\text { Structural Break } \\
\text { (Politicization) }\end{array}$ & 0.29202 & 0.06183 & 4.723 & $<0.001 * * *$ \\
\hline \multicolumn{5}{|c|}{ 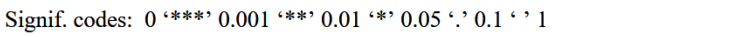 } \\
\hline \multicolumn{5}{|c|}{$\begin{array}{l}\text { Residual standard error: } 0.5716 \text { on } 1088 \text { degrees of freedom } \\
\text { Multiple R-squared: } 0.6658 \text {, Adjusted R-squared: } 0.6642 \\
\text { F-statistic: } 433.5 \text { on } 5 \text { and } 1088 \text { DF, p-value: }<2.2 \mathrm{e}-16\end{array}$} \\
\hline
\end{tabular}

Table 6: VAR model with the series of tweets sharing problematic information sources as the dependent variable.

known for spreading online misinformation, misinformation or hyper-partisan and misleading information (some of which offline, an additional indicator of problematic sources, see Bastos 2019), while pro-vaccine sources were grouped with the scientific and debunking ones. A third cluster grouped political sources, and the fourth included mainstream media along with institutional information sources.

Considering the results of the correspondence analysis, it appears clear that the main dimension (accounting for $70.2 \%$ of the total variance) contrasts the alternative and problematic information sources against the mainstream and scientific ones, while the political cluster seems to lie in between these two polarities. This result corroborates the idea that the vaccine-related information environment mirrors the contrasts between anti-vax and pro-vax perspectives, or, in other words, is characterized by a consistent degree of homophily and polarization.

The quantity of tweets sharing problematic news sources varied over time, and the analyses showed that politicization was associated with an increasing number of both total tweets and those sharing problematic information sources (RQ3). A significant structural break in the series of tweets sharing problematic sources was found, indeed, in almost perfect correspondence with the structural break of the whole series of tweets, that is, during the political debate on the mandatory vaccinations $\operatorname{law}^{8}$. A second, less pronounced, break in the series of problematic tweets was found after 2018-08-18, some weeks before the school year began and during the government led by the League and Five Star Movement, two parties that promised the abolition of the Lorenzin decree, thus raising expectations about change in the vaccinations norms (Lovari et al., 2020).

This evidence suggested, therefore, that politicization had a significant impact on the whole Twitter information flow and, more specifically, on the spread of misinformation. A VAR regression further confirmed this observation. The

\footnotetext{
${ }^{8}$ The structural break in the whole series was found between 2017-04-17 and 2017-09-28, while the one in the tweets sharing problematic sources was found between 2017-04-16 and 2017-0927.
}

\begin{tabular}{lllll}
\hline Coefficients & Estimate & Std. Error & $\mathrm{t}$ value & $\operatorname{Pr}(>|\mathrm{t}|)$ \\
\hline Problematic Lag 1 & -0.009643 & 0.009147 & -1.054 & 0.2920 \\
News Lag 1 & 0.550706 & 0.030731 & 17.920 & $<0.001 * * *$ \\
Problematic Lag 2 & -0.003379 & 0.009071 & -0.373 & 0.7096 \\
News Lag 2 & 0.051055 & 0.030770 & 1.659 & 0.0974. \\
Const & 0.146301 & 0.017434 & 8.392 & $<0.001 * * *$ \\
Structural Break & 0.131500 & 0.018823 & 6.986 & $<0.001 * * *$ \\
(Politicization) & & &
\end{tabular}

Residual standard error: 0.5716 on 1088 degrees of freedom

Multiple R-squared: 0.6658 , Adjusted R-squared: 0.6642

F-statistic: 433.5 on 5 and $1088 \mathrm{DF}, \mathrm{p}$-value: $<2.2 \mathrm{e}-16$

Table 7: VAR model with the news media coverage as the dependent variable.

\begin{tabular}{|c|c|c|c|c|c|}
\hline Period & Institutional & $\begin{array}{l}\text { Health and } \\
\text { Scientific }\end{array}$ & News & Political & Problematic \\
\hline $\begin{array}{l}\text { Segment } 1 \text { ( } 442 \text { days) } \\
(2016-02-01 / 2017-04-17)\end{array}$ & $\begin{array}{l}433 \\
(\mathrm{M}=0.980 \\
\mathrm{I}=100)\end{array}$ & $\begin{array}{l}5179 \\
(\mathrm{M}=11.7 \\
\mathrm{I}=100)\end{array}$ & $\begin{array}{l}25365 \\
(M=57.4 \\
\mathrm{I}=100)\end{array}$ & $\begin{array}{l}3469 \\
(\mathrm{M}=7.85 ; \\
\mathrm{I}=100)\end{array}$ & $\begin{array}{l}3807 \\
(\mathrm{M}=8.61 ; \\
\mathrm{I}=100)\end{array}$ \\
\hline $\begin{array}{l}\text { Segment } 2 \text { ( } 165 \text { days }) \\
(2017-04-18 / 2017-09-28)\end{array}$ & $\begin{array}{l}942 \\
(\mathrm{M}=5.71 ; \\
\mathrm{I}=583)\end{array}$ & $\begin{array}{l}4112 \\
(M=24.9 \\
I=213)\end{array}$ & $\begin{array}{l}45716 \\
(\mathrm{M}=277.0 \\
\mathrm{I}=483)\end{array}$ & $\begin{array}{l}9382 \\
(\mathrm{M}=56.9 ; \\
\mathrm{I}=724)\end{array}$ & $\begin{array}{l}8881 \\
(\mathrm{M}=53.8 ; \\
\mathrm{I}=625)\end{array}$ \\
\hline $\begin{array}{l}\text { Segment } 3 \text { (491 days) } \\
(2017-09-29 / 2019-01-31)\end{array}$ & $\begin{array}{l}750 \\
(\mathrm{M}=1.53 ; \\
\mathrm{I}=156)\end{array}$ & $\begin{array}{l}4409 \\
(\mathrm{M}=8.98 \\
\mathrm{I}=76.6)\end{array}$ & $\begin{array}{l}27857 \\
(\mathrm{M}=56.7 \\
\mathrm{I}=98.9)\end{array}$ & $\begin{array}{l}4170 \\
(\mathrm{M}=8.49 ; \\
\mathrm{I}=108)\end{array}$ & $\begin{array}{l}7843 \\
(\mathrm{M}=16.0 \\
\mathrm{I}=185)\end{array}$ \\
\hline
\end{tabular}

Table 8: Total number of tweets that shared information sources included in each cluster and, in parentheses, the average number by day (M) and the index number (I).

analysis found not only that the increase of news coverage at times t-1 was associated with a significant $(\mathrm{p}<0.001)$ increase of tweets sharing problematic information sources at times $\mathrm{t}$ (the next day), but also that politicization, represented by the structural break matching the political debate of the mid-2017, kept being significantly associated with the increase in the spread of disinformation $(\mathrm{p}<0.001)$.

The model showed also that politicization (but not the series of tweets sharing problematic information sources) was associated with the volume of media coverage $(p<0.001)$ (Table 7).

Considering the changes in news sources shared before, during and after the peak of vaccine-related discussion in the middle of 2017 (RQ4), it can be observed (Table 8) that during the most heated period of discussion on Twitter there was a lack of scientific and quality health information: while, on average, the number of tweets sharing misinformation was about 6 times higher than the previous period, and similarly the volume of the other categories of information sources increased from about five to about seven times, the average number tweets sharing scientific sources increased by about two times only (Table 8). Moreover, while all the categories increased, on average, their presence on Twitter from before and after the debate on mandatory vaccination of the mid2017 , the health and scientific cluster was the only one that decreased its online presence. 


\section{Discussion and conclusions}

It has been observed that the politicization of a crucial health issue such as vaccinations can be a vehicle for the spread of disinformation (Lovari, Maritino \& Righetti, 2020). This study found further evidence of the role of politicization in increasing the volume of problematic information on social media. Indeed, it showed that the heated political debate on the mandatory vaccination law was associated (also keeping constant the news media coverage variable) with an increase in the number of tweets sharing problematic information sources such as conspiracy, anti-vax, hyperpartisan and blacklisted sources (Blaskiewicz, 2013; Briones et al., 2012; Douglas et al., 2019; Mancosu et al., 2017). It was moreover showed that during the political debate about the law, when the attention to the topics was the highest, the volume of tweets sharing scientific and health information sources increased much less (just two times that of the previous period) compared with the volume of the tweets sharing problematic information, which increased, on average, of over 6 times.

Sources of problematic information were shared on Twitter both before and after the promulgation of the law on mandatory child vaccination. However, this study showed that their quantity increased after the mid-2017, compared to the first period taken into consideration, demonstrating that vaccine-related disinformation has not ceased to be a problem and suggesting that the politicization of the topic (Gollust et al., 2016; Lovari et al., 2020) might have had a long-lasting impact on the online attention devoted to it, a matter that deserves further examination. At the same time, the number of tweets sharing scientific information sources decreased.

The study confirmed the role of homophily (Lazarsfeld \& Merton, 1954; McPherson, Smith-Lovin, \& Cook 2001) in structuring the networks of social media users and information sources involved in the discussion around the controversial and polarizing issue of vaccines (Schmidt et al., 2018). The sharp distinction between the pro-vaccine and antivaccine cluster of information sources indicates that Twitter users with contrasting views relied on different sources of information. This could be interpreted as a signal that social media users are trapped in echo-chambers (Gunaratne et al., 2019; Schmidt et al., 2018), but also as traces of a strategic use of information sources shared on Twitter to support and spread a view (Kata, 2010, 2012; Moran, Lucas, Everhart, Morgan, \& Prickett, 2016), since the sharing of URLs can be associated to persuasive writing style (Addawood, Badawy, Lerman, \& Ferrara, 2019, p. 19).

This research also stressed the methodological relevance of homophily for the digital analysis of subcultures. The performed analysis showed that the anti-vaccine sources were clustered together with alternative therapies and conspiracy theories websites. The anti-vaccines movement, indeed, often goes hand in hand with the endorsement of naturalistic theses and alternative therapies, while official medicine becomes the subject of conspiracy theories (Blaskiewicz, 2013; Briones et al., 2012; Douglas et al., 2019; Mancosu et al., 2017) which accuse governments and pharmaceutical companies of getting rich at the expense of the people's health. Because of the capability to identify different facets of socio-cultural phenomena, the method could be further developed and applied to the analysis of a variety of cases.

This study has also some limitations that must be noted. First, the keyword-based strategy used to collect the data, although as neutral as possible, could have introduced some biases. Although completeness and unbiasedness are hard to achieve in studies like this, given the many and unpredictable ways people talk about a topic online, future research could try to use a wider set of keywords to achieve a higher level of completeness. Another limitation is the limited time period taken into account. Three years could be a too short period of time to fully understand trends, and other analyses could consider a longer time window. However, this choice permitted the analysis of an equal amount of time before and after the promulgation of the law on mandatory vaccinations. Also the "source-based" approach (Pierri, Artoni, \& Ceri, 2020) used in this study is limited in that it takes into account just the tweets that included URLs. Future studies should take into consideration also all the other messages that can be vehicle of misinformation or scientific information, and use more sophisticated measures able to account for the complexity of the online information environment.

In conclusion, the study demonstrates that the heated debate sparked by the Italian law on mandatory child vaccination and the subsequent politicization of the topic created a breeding ground for problematic information on Twitter, and that misinformation on vaccines, alongside polarization, is still a problem. The relation between politicization and health misinformation deserve further analyses, as do the role and impact of scientific communication on social media and its interactions with misinformation and politicization of health.

\section{References}

Ache, K. A., \& Wallace, L. S. (2008). Human Papillomavirus Vaccination Coverage on YouTube. American Journal of Preventive Medicine, 35(4), 389-392. doi:10.1016/j.amepre.2008.06.029

AGCOM. (2018). News vs. Fake in the Information System, 122.

Ajovalasit, S., Dorgali, V., Mazza, A., Onofrio, A. D., \& Manfredi, P. (2019). Evidence of distrust and disorientation towards immunization on online social media after contrasting political communication on vaccines. Results from an analysis of Twitter data in Italy. arXiv preprint arXiv:2002.00846.

Bakshy, E., Messing, S., \& Adamic, L. A. (2015). Exposure to ideologically diverse news and opinion on Facebook. Science, 348(6239), 1130-1132. doi:10.1126/science.aaa1160

Barberá, P., Jost, J. T., Nagler, J., Tucker, J. A., \& Bonneau, R. (2015). Tweeting From Left to Right: Is Online Political Communication More Than an Echo Chamber? Psychological Science, 26(10), 1531-1542. doi:10.1177/0956797615594620 
Bastian, M., Heymann, S., \& Jacomy, M. (2009). Gephi: An open source software for exploring and manipulating networks. In Third international AAAI conference on weblogs and social media.

Bastos, M. T., 2019. “This Account Doesn't Exist: Tweet Decay and the Politics of Deletion in the Brexit Debate". Available at SSRN: https://ssrn.com/abstract=3485789

Bean, S. J. (2011). Emerging and continuing trends in vaccine opposition website content. Vaccine, 29(10), 1874-1880. doi:10.1016/j.vaccine.2011.01.003

Betsch, C., Renkewitz, F., Betsch, T., \& Ulshöfer, C. (2010). The Influence of Vaccine-critical Websites on Perceiving Vaccination Risks. Journal of Health Psychology, 15(3), 446-455. doi:10.1177/1359105309353647

Blankenship, E. B., Goff, M. E., Yin, J., Tse, Z. T. H., Fu, K.-W., Liang, H., ... Fung, I. C.-H. (2018). Sentiment, Contents, and Retweets: A Study of Two VaccineRelated Twitter Datasets. The Permanente Journal, 22. doi:10.7812/TPP/17-138

Blaskiewicz, R. (2013). The Big Pharma conspiracy theory. Medical Writing, 22(4), 259-261. doi:10.1179/2047480613Z.000000000142

Blondel, V. D., Guillaume, J.-L., Lambiotte, R., \& Lefebvre, E. (2008). Fast unfolding of communities in large networks. Journal of Statistical Mechanics: Theory and Experiment, 2008(10), P10008.

Bode, L., \& Vraga, E. K. (2018). See Something, Say Something: Correction of Global Health Misinformation on Social Media. Health Communication, 33(9), 1131-1140. doi:10.1080/10410236.2017.1331312

Bodemer, N., Müller, S. M., Okan, Y., Garcia-Retamero, R., \& Neumeyer-Gromen, A. (2012). Do the media provide transparent health information? A cross-cultural comparison of public information about the HPV vaccine. Vaccine, 30(25), 3747-3756. doi:10.1016/j.vaccine.2012.03.005

Box-Steffensmeier, J. M., Freeman, J. R., Hitt, M. P., \& Pevehouse, J. C. (2014). Time series analysis for the social sciences. Cambridge University Press. Briones, R., Nan, X., Madden, K., \& Waks, L. (2012). When Vaccines Go Viral: An Analysis of HPV Vaccine Coverage on YouTube. Health Communication, 27(5), 478-485. doi:10.1080/10410236.2011.610258

Broniatowski, D. A., Jamison, A. M., Qi, S., AlKulaib, L., Chen, T., Benton, A., ... Dredze, M. (2018). Weaponized Health Communication: Twitter Bots and Russian Trolls Amplify the Vaccine Debate. American Journal of Public Health, 108(10), 1378-1384. doi:10.2105/AJPH.2018.304567

Bruns, A. (2019). Are filter bubbles real? John Wiley \& Sons.

Burioni, R. (2018). MedicalFacts. Medicalfacts. https://www.medicalfacts.it/.
Casula, M., \& Toth, F. (2018). The Yellow-Green Government and the Thorny Issue of Routine Childhood Vaccination. Italian Political Science, 13(2), 104-114.

Chakraborty, P., Colditz, J. B., Silvestre, A. J., Friedman, M. R., Bogen, K. W., \& Primack, B. A. (2017). Observation of public sentiment toward human papillomavirus vaccination on Twitter. Cogent Medicine, 4(1), 1390853. doi:10.1080/2331205X.2017.1390853

Chirico, F. (2018). The new Italian mandatory vaccine Law as a health policy instrument against the anti-vaccination movement. Annali Di Igiene Medicina Preventiva E Di Comunità, (30), 251-256. doi:10.7416/ai.2018.2217

Clarke, C. E., Dixon, G. N., Holton, A., \& McKeever, B. W. (2015). Including "Evidentiary Balance" in News Media Coverage of Vaccine Risk. Health Communication, 30(5), 461-472. doi:10.1080/10410236.2013.867006

Colleoni, E., Rozza, A., \& Arvidsson, A. (2014). Echo Chamber or Public Sphere? Predicting Political Orientation and Measuring Political Homophily in Twitter Using Big Data. Journal of Communication, 64(2), 317-332. doi: $10.1111 /$ jcom. 12084

Comunello, F., Mulargia, S., \& Parisi, L. (2017). Non Guardarmi, non ti sento. Processi di sense giving nella controversia sui vaccini infantili tra gli utenti di Facebook. Problemi Dell'informazione, (3), 431-458. doi:10.1445/88099

Conover, M. D., Ratkiewicz, J., Francisco, M., Gonçalves, B., Menczer, F., \& Flammini, A. (2011). Political polarization on twitter. In Fifth international AAAI conference on weblogs and social media.

Covolo, L., Ceretti, E., Passeri, C., Boletti, M., \& Gelatti, U. (2017). What arguments on vaccinations run through YouTube videos in Italy? A content analysis. Human Vaccines \& Immunotherapeutics, 13(7), 1693-1699. doi:10.1080/21645515.2017.1306159

Csardi G, Nepusz T (2006). The igraph software package for complex network research, InterJournal, Complex Systems 1695. 2006. http://igraph.org

Dandekar, P., Goel, A., \& Lee, D. T. (2013). Biased assimilation, homophily, and the dynamics of polarization. Proceedings of the National Academy of Sciences, 110(15), 5791-5796. doi:10.1073/pnas.1217220110

Danovaro-Holliday, M. C., Wood, A. L., \& LeBaron, C. W. (2002). Rotavirus Vaccine and the News Media, 1987-2001. JAMA, 287(11), 1455-1462. doi:10.1001/jama.287.11.1455

Dixon, G. N., \& Clarke, C. E. (2013). Heightening Uncertainty Around Certain Science: Media Coverage, False Balance, and the Autism-Vaccine Controversy. Science Communication, 35(3), 358-382. doi: $10.1177 / 1075547012458290$

Donzelli, G., Palomba, G., Federigi, I., Aquino, F., Cioni, L., Verani, M., ... Lopalco, P. (2018). Misinformation on 
vaccination: A quantitative analysis of YouTube videos. Human Vaccines \& Immunotherapeutics, 14(7), 1654-1659. doi:10.1080/21645515.2018.1454572

Douglas, K. M., Uscinski, J. E., Sutton, R. M., Cichocka, A., Nefes, T., Ang, C. S., \& Deravi, F. (2019). Understanding conspiracy theories. Political Psychology, 40, 3-35.

Dubois, E., \& Blank, G. (2018). The echo chamber is overstated: the moderating effect of political interest and diverse media. Information, Communication \& Society, 21(5), 729745.

Dunn, A. G., Surian, D., Leask, J., Dey, A., Mandl, K. D., \& Coiera, E. (2017). Mapping information exposure on social media to explain differences in HPV vaccine coverage in the United States. Vaccine, 35(23), 3033-3040. doi:10.1016/j.vaccine.2017.04.060

Ekram, S., Debiec, K. E., Pumper, M. A., \& Moreno, M. A. (2019). Content and Commentary: HPV Vaccine and YouTube. Journal of Pediatric and Adolescent Gynecology, 32(2), 153-157. doi:10.1016/j.jpag.2018.11.001

European Commission. (2018). A multi-dimensional approach to disinformation: Report of the independent high level group on fake news and online disinformation.

European Commission. (2019). Ten Actions Towards Vaccination for All.

Facebook. (2019, March). Combatting Vaccine Misinformation - Facebook Newsroom.

Fadda, M., Allam, A., \& Schulz, P. J. (2015). Arguments and sources on Italian online forums on childhood vaccinations: Results of a content analysis. Vaccine, 33(51), 7152-7159. doi:10.1016/j.vaccine.2015.11.007

Faris, R., Roberts, H., Etling, B., Bourassa, N., Zuckerman, E., \& Benkler, Y. (2017). Partisanship, propaganda, and disinformation: Online media and the 2016 US presidential election. Berkman Klein Center Research Publication, 6.

Filia, A., Bella, A., Del Manso, M., Baggieri, M., Magurano, F., \& Rota, M. C. (2017). Ongoing outbreak with well over 4,000 measles cases in Italy from January to end August 2017 - what is making elimination so difficult? Eurosurveillance, 22(37), 30614. doi:10.2807/15607917.ES.2017.22.37.30614

Fletcher, R., Cornia, A., Graves, L., \& Nielsen, R. K. (2018). Measuring the reach of "fake news" and online disinformation in Europe, 10.

FNOMCeO. (2018). Dottore... ma è vero che? Dottore, ma è vero che... ? https://dottoremaeveroche.it/.

Forster, A., Wardle, J., Stephenson, J., \& Waller, J. (2010). Passport to Promiscuity or Lifesaver: Press Coverage of HPV Vaccination and Risky Sexual Behavior. Journal of Health Communication, 15(2), 205-217. doi:10.1080/10810730903528066

Gesser-Edelsburg, A., Diamant, A., Hijazi, R., \& Mesch, G. S. (2018). Correcting misinformation by health organizations during measles outbreaks: A controlled experiment. PLOS ONE, 13(12), e0209505. doi:10.1371/journal.pone.0209505

Ghanbari, Z., Yousefi Nejad, M., Jafari Navimipour, N., \& Hosseinzadeh, M. (2019). Detection of Twitter Users' Attitudes about Flu Vaccine based on the Content and Sentiment Analysis of the Sent Tweets. Journal of Health and Biomedical Informatics, 5(4), 494-481.

Giglietto, F., Iannelli, L., Rossi, L., Valeriani, A., Righetti, N., Carabini, F., ... Zurovac, E. (2018). Mapping italian news media political coverage in the lead-up to 2018 general election. Available at SSRN 3179930.

Giglietto, F., Iannelli, L., Valeriani, A., \& Rossi, L. (2019a). "Fake news" is the invention of a liar: How false information circulates within the hybrid news system. Current Sociology, 67(4), 625-642. doi:10.1177/0011392119837536

Giglietto, F., Righetti, N., Marino, G., \& Rossi, L. (2019b). Multi-party media partisanship attention score. Estimating partisan attention of news media sources using Twitter data in the lead-up to 2018 Italian election. Comunicazione Politica, 20(1), 85-108.

Giglietto, F., Righetti, N., Rossi, L., \& Marino, G. (2020). It takes a village to manipulate the media: coordinated link sharing behavior during 2018 and 2019 Italian elections. Information, Communication \& Society, 1-25.

Gollust, S. E., Attanasio, L., Dempsey, A., Benson, A. M., \& Fowler, E. F. (2013). Political and News Media Factors Shaping Public Awareness of the HPV Vaccine. Women's Health Issues, 23(3), e143-e151. doi:10.1016/j.whi.2013.02.001

Gollust, S. E., LoRusso, S. M., Nagler, R. H., \& Fowler, E. F. (2016). Understanding the role of the news media in HPV vaccine uptake in the United States: Synthesis and commentary. Human Vaccines \& Immunotherapeutics, 12(6), 1430-1434. doi:10.1080/21645515.2015.1109169

Grant, L., Hausman, B. L., Cashion, M., Lucchesi, N., Patel, K., \& Roberts, J. (2015). Vaccination Persuasion Online: A Qualitative Study of Two Pro-vaccine and Two VaccineSkeptical Websites. Journal of Medical Internet Research, 17(5), e133. doi:10.2196/jmir.4153

Guidry, J. P., Meganck, S. L., Lovari, A., Messner, M., Medina-Messner, V., Sherman, S., \& Adams, J. (2019). Tweeting about \#Diseases and \#Publichealth: Communicating Global Health Issues across Nations. Health communication, 1-9.

Gunaratne, K., Coomes, E. A., \& Haghbayan, H. (2019). Temporal trends in anti-vaccine discourse on Twitter. Vaccine, 37(35), 4867-4871.

Habel, M. A., Liddon, N., \& Stryker, J. E. (2009). The HPV Vaccine: A Content Analysis of Online News Stories. Journal of Women's Health (15409996), 18(3), 401-407. doi:10.1089/jwh.2008.0920 
Harrison, D., Wilding, J., Bowman, A., Fuller, A., Nicholls, S. G., Pound, C. M., ... Sampson, M. (2016). Using YouTube to Disseminate Effective Vaccination Pain Treatment for Babies. PLOS ONE, 11(10), e0164123. doi:10.1371/journal.pone.0164123

Hilton, S., Hunt, K., Langan, M., Bedford, H., \& Petticrew, M. (2010). Newsprint media representations of the introduction of the HPV vaccination programme for cervical cancer prevention in the UK (20052008). Social Science \& Medicine, 70(6), 942-950. doi:10.1016/j.socscimed.2009.11.027

Himelboim, I., Xiao, X., Lee, D. K. L., Wang, M. Y., \& Borah, P. (2019). A Social Networks Approach to Understanding Vaccine Conversations on Twitter: Network Clusters, Sentiment, and Certainty in HPV Social Networks. Health Communication, 1-9. doi:10.1080/10410236.2019.1573446

Husson, F., Lê, S., \& Pagès, J. (2017). Exploratory multivariate analysis by example using $\mathrm{R}$. CRC press.

ISS. (2018a). ISS Salute. ISSalute. https://www.issalute.it/.

ISS. (2019). Morbillo \& Rosolia News. Rapporto n. 48, gennaio 2019

Kata, A. (2010). A postmodern Pandora's box: Antivaccination misinformation on the Internet. Vaccine, 28(7), 1709-1716. doi:10.1016/j.vaccine.2009.12.022

Kata, A. (2012). Anti-vaccine activists, Web 2.0, and the postmodern paradigm overview of tactics and tropes used online by the anti-vaccination movement. Vaccine, 30(25), 3778-3789. doi:10.1016/j.vaccine.2011.11.112

Larson, H. J. (2018, October). The biggest pandemic risk? Viral misinformation. Nature.

Lazarsfeld, P. F., Merton, R. K., \& others. (1954). Friendship as a social process: A substantive and methodological analysis. Freedom and Control in Modern Society, 18(1), 18-66.

Lazer, D. M., Baum, M. A., Benkler, Y., Berinsky, A. J., Greenhill, K. M., Menczer, F., ... others. (2018). The science of fake news. Science, 359(6380), 1094-1096.

Lin, C. A., \& Lagoe, C. (2013). Effects of News Media and Interpersonal Interactions on H1N1 Risk Perception and Vaccination Intent. Communication Research Reports, 30(2), 127-136. doi:10.1080/08824096.2012.762907

Lovari, A., Martino, V., \& Righetti, N. (2020). Blurred Shots: Investigating Information Crisis around Vaccination in Italy. American Behavioral Scientist.

Love, B., Himelboim, I., Holton, A., \& Stewart, K. (2013). Twitter as a source of vaccination information: Content drivers and what they are saying. American Journal of Infection Control, 41(6), 568-570.

Mancosu, M., Vassallo, S., \& Vezzoni, C. (2017). Believing in Conspiracy Theories: Evidence from an Exploratory Analysis of Italian Survey Data.
South European Society and Politics, 22(3), 327-344. doi:10.1080/13608746.2017.1359894

McPherson, M., Smith-Lovin, L., \& Cook, J. M. (2001). Birds of a feather: Homophily in social networks. Annual review of sociology, 27(1), 415-444.

Moran, M. B., Lucas, M., Everhart, K., Morgan, A., \& Prickett, E. (2016). What makes anti-vaccine websites persuasive? A content analysis of techniques used by anti-vaccine websites to engender anti-vaccine sentiment. Journal of Communication in Healthcare, 9(3), 151-163. doi:10.1080/17538068.2016.1235531

Pariser, E. (2011). The filter bubble: How the new personalized web is changing what we read and how we think. Penguin.

Pierri, F., Artoni, A., \& Ceri, S. (2020). Investigating Italian disinformation spreading on Twitter in the context of 2019 European elections. PloS one, 15(1), e0227821.

Pinterest. (2019, August). Bringing authoritative vaccine results to Pinterest search. Pinterest Newsroom. https://newsroom.pinterest.com/en/post/bringingauthoritative-vaccine-results-to-pinterest-search.

Radzikowski, J., Stefanidis, A., Jacobsen, K. H., Croitoru, A., Crooks, A., \& Delamater, P. L. (2016). The Measles Vaccination Narrative in Twitter: A Quantitative Analysis. JMIR Public Health and Surveillance, 2(1), e1. doi:10.2196/publichealth.5059

$\mathrm{R}$ Core Team (2019). A language and environment for statistical computing. Vienna, Austria: R Foundation for Statistical Computing; 2012. URL Https://Www. R-Project. Org.

Rudis, B. (2016). Longurl: Expand Short 'URLs'. R package version 0.3.2.

Salathé, M., \& Khandelwal, S. (2011). Assessing Vaccination Sentiments with Online Social Media: Implications for Infectious Disease Dynamics and Control. PLOS Computational Biology, 7(10), e1002199. doi:10.1371/journal.pcbi.1002199

Samantray, A., \& Pin, P. (2019). Credibility of climate change denial in social media. Palgrave Communications, $5(1), 1-8$

Sastry, S., \& Lovari, A. (2017). Communicating the ontological narrative of Ebola: an emerging disease in the time of "epidemic 2.0". Health communication, 32(3), 329-338.

Schmidt, A. L., Zollo, F., Scala, A., Betsch, C., \& Quattrociocchi, W. (2018). Polarization of the vaccination debate on Facebook. Vaccine, 36(25), 3606-3612. doi:10.1016/j.vaccine.2018.05.040

Schmidt, A. L., Zollo, F., Vicario, M. D., Bessi, A., Scala, A., Caldarelli, G., ... Quattrociocchi, W. (2017). Anatomy of news consumption on Facebook. Proceedings of the National Academy of Sciences, 114(12), 3035-3039. doi:10.1073/pnas.1617052114 
Skea, Z. C., Entwistle, V. A., Watt, I., \& Russell, E. (2008). "Avoiding harm to others" considerations in relation to parental measles, mumps and rubella (MMR) vaccination discussions analysis of an online chat forum. Social Science \& Medicine, 67(9), 1382-1390. doi:10.1016/j.socscimed.2008.07.006

Signorelli, C., Odone, A., Cella, P., \& Iannazzo, S. (2018). Childhood vaccine coverage in Italy after the new law on mandatory immunization. Ann Ig, 30(Suppl 1), 1-10.

Smith, M. J., Ellenberg, S. S., Bell, L. M., \& Rubin, D. M. (2008). Media Coverage of the Measles-Mumps-Rubella Vaccine and Autism Controversy and Its Relationship to MMR Immunization Rates in the United States. Pediatrics, 121(4), e836-e843. doi:10.1542/peds.2007-1760

Speers, T., \& Lewis, J. (2004). Journalists and jabs: Media coverage of the MMR vaccine. Communication \& Medicine, 1(2), 171-181. doi:10.1515/come.2004.1.2.171

Stroud, N. J. (2010). Polarization and Partisan Selective Exposure. Journal of Communication, 60(3), 556-576. doi:10.1111/j.1460-2466.2010.01497.x

Sunstein, C. R. (2001a). Echo chambers: Bush v. Gore, impeachment, and beyond. Princeton University Press Princeton, NJ.

Sunstein, C. R. (2001b). Republic.Com. Princeton university press.

Tafuri, S., Gallone, M. S., Gallone, M. F., Zorico, I., Aiello, V., \& Germinario, C. (2014). Communication about vaccinations in Italian websites: A quantitative analysis. Human Vaccines \& Immunotherapeutics, 10(5), 1416-1420. doi: $10.4161 /$ hv. 28268

Tavoschi, L., Quattrone, F., D’Andrea, E., Ducange, P., Vabanesi, M., Marcelloni, F., \& Lopalco, P. L. (2020). Twitter as a sentinel tool to monitor public opinion on vaccination: an opinion mining analysis from September 2016 to August 2017 in Italy. Human Vaccines \& Immunotherapeutics, 1-8.

Tucker, J. A., Guess, A., Barberá, P., Vaccari, C., Siegel, A., Sanovich, S., ... Nyhan, B. (2018). Social media, political polarization, and political disinformation: A review of the scientific literature. Political Polarization, and Political Disinformation: A Review of the Scientific Literature (March 19, 2018).

Twitter. (2019, May). Helping you find reliable public health information on Twitter. https://blog.twitter.com/en_us/topics/company/2019/helpingyou-find-reliable-public-health-information-ontwitter.html.

Vraga, E. K., \& Bode, L. (2017). Using Expert Sources to Correct Health Misinformation in Social Media. Science Communication, 39(5), 621-645. doi:10.1177/1075547017731776
Ward, J. K., Peretti-Watel, P., Larson, H. J., Raude, J., \& Verger, P. (2015). Vaccine-criticism on the internet: New insights based on French-speaking websites. Vaccine, 33(8), 1063-1070. doi:10.1016/j.vaccine.2014.12.064

Wardle, C., \& Derakhshan, H. (2017). Information disorder: Toward an interdisciplinary framework for research and policy making. Council of Europe report, 27.

WHO. (2019a). Ten health issues WHO will tackle this year. https://www.who.int/emergencies/ten-threats-toglobal-health-in-2019.

WHO. (2019b). Vaccination: European Commission and World Health Organization join forces to promote the benefits of vaccines. https://www.who.int/news-room/detail/1209-2019-vaccination-european-commission-and-worldhealth-organization-join-forces-to-promote-the-benefits-ofvaccines.

Witteman, H. O., \& Zikmund-Fisher, B. J. (2012). The defining characteristics of Web 2.0 and their potential influence in the online vaccination debate. Vaccine, 30(25), 3734-3740. doi:10.1016/j.vaccine.2011.12.039

Yuan, X., Schuchard, R. J., \& Crooks, A. T. (2019). Examining Emergent Communities and Social Bots Within the Polarized Online Vaccination Debate in Twitter. Social Media + Society, 5(3), 2056305119865465. doi:10.1177/2056305119865465

Zeileis, A., Leisch, F., Hornik, K., \& Kleiber, C. (2001). strucchange. An R package for testing for structural change in linear regression models.

Zhang, C., Gotsis, M., \& Jordan-Marsh, M. (2013). Social media microblogs as an HPV vaccination forum. Human Vaccines \& Immunotherapeutics, 9(11), 2483-2489. doi:10.4161/hv.25599 